\title{
Pediatric Colonoscopy: The Changing Patterns and Single Institutional Experience Over a Decade
}

\author{
Jae Hong Park \\ Department of Pediatrics, Pusan National University School of Medicine, Yangsan, Korea
}

The safety and effectiveness of pediatric colonoscopy for lower gastrointestinal tract diseases have been established in Korea for about 30 years. Both diagnostic and therapeutic colonoscopies have had many advances in terms of operator skill and experience and are now being performed by most pediatric gastroenterologists. Pediatric colonoscopy is different in many aspects from that of adults, such as expected diagnoses, patient management, bowel preparation, selection criteria for sedation, and instrument selection. In this review, the author presents practical information on pediatric colonoscopy, the author's experiences, and the changes in colonoscopy practices over a decade in a tertiary hospital in Korea. Clin Endosc 2018;51:137-141

Key Words: Gastrointestinal disease; Colonoscopy; Child

\section{INTRODUCTION}

Flexible colonoscopy in children was introduced slightly later than upper gastrointestinal endoscopy. In the literature, reports of pediatric colonoscopy first appeared in late 1970s. ${ }^{1}$ Since the development of the equipment, colonoscopy has become possible in all children, including newborn infants. Both diagnostic and therapeutic colonoscopies have had many advances in terms of operator skill and experience and are now being performed by most pediatric gastroenterologists. However, pediatric colonoscopy is far behind that of adults in the development of endoscopic techniques, especially in the field of therapeutic endoscopy, such as endoscopic mucosal resection or endoscopic submucosal dissection. Though successful cecal intubation is not always easy in any patient age, there are additional aspects requiring considerations in pediatric colo-

Received: February 11, 2018 Accepted: March 23, 2018

Correspondence: Jae Hong Park

Department of Pediatrics, Pusan National University School of Medicine, 20 Geumo-ro, Mulgeum-eup, Yangsan 50612, Korea

Tel: +82-55-360-2180, Fax: +82-55-360-2181, E-mail: jhongpark@pusan.ac.kr ORCID: https://orcid.org/0000-0002-5274-7064

(cc) This is an Open Access article distributed under the terms of the Creative Commons Attribution Non-Commercial License (http://creativecommons.org/ licenses/by-nc/3.0) which permits unrestricted non-commercial use, distribution, and reproduction in any medium, provided the original work is properly cited. noscopy, including difficulties in bowel preparation, sedation and poor cooperation. ${ }^{1}$

The history of pediatric colonoscopy in Korea spans about 30 years and has accomplished significant progress in this field. The author aims to present this review, focusing on the general principles of pediatric colonoscopy and the changes in colonoscopy practices over a decade in a tertiary hospital in Korea.

\section{INDICATIONS AND CONTRAINDICATIONS OF COLONOSCOPY}

In Western countries, the main indication of diagnostic pediatric colonoscopy is suspected inflammatory bowel disease (IBD) and follow-up assessment of IBD treatment efficiency, and that of therapeutic pediatric colonoscopy is polypectomy. Colonoscopy can be used not only for observation of the whole colon and distal ileum, and collection of tissues for histological examination, but also for hemostasis, dilating strictures, or decompressing obstructed bowels. Most pediatric colonoscopists in Korea recently are performing these procedures described above.

The contraindications for colonoscopy are similar to those 
for upper gastrointestinal endoscopy. Colonoscopy should not be performed if bowel perforation or bowel ischemia is suspected. Adequate bowel preparation is prerequisite.

\section{PREPARATION FOR COLONOSCOPY}

In pediatric colonoscopy, colon can be cleaned in the same way as in adults. In infants, small-volume enemas with clear liquids for 12-24 hours can achieve adequate preparation. In older children, bowel cleansing can be performed with colonic lavage solutions that contain a non-absorbable solution of polyethylene glycol and electrolytes. The method utilizable to cleanse the colon depends on the age and cooperation of the child, and the individual examiner's preference.

\section{SEDATION IN PEDIATRIC ENDOSCOPY}

With increased experience, colonoscopy can now be performed safely with intravenous sedation on almost all patients. ${ }^{2}$ The approach to sedation varies among institutions and physicians. Many pediatric endoscopists have performed colonoscopy under general anesthesia in children with intolerance to colonoscopy under conscious sedation or fear of complications. ${ }^{3,4}$ However, the author has performed all colonoscopy under conscious sedation only.

\section{NEW TECHNOLOGIES IN PEDIATRIC COLONOSCOPY}

There is evidence that success rates of cecal intubation in the difficult colon can be improved using nonstandard endoscopes, such as upper gastrointestinal endoscope, enteroscope, and variable-stiffness colonoscope. Colonoscopes of variable stiffness have been developed to decrease loop formation and assist with loop reduction. Although they are available for use in pediatric patients, variable stiffening of the endoscope should not be used to replace the basic endoscopic techniques such as minimal loop formation and rapid loop reduction. ${ }^{5}$ Accessories that may facilitate difficult colonoscopy include an overtube, used largely in the sigmoid colon, and transparent caps used on the tips of colonoscopies. The use of an overtube in pediatric colonoscopy is limited.

Cap-assisted colonoscopy (CAC), in which a small transparent cap is attached to the tip of the colonoscope, can help depress haustral folds, thereby decreasing the blind mucosal surface area. Some studies demonstrated that CAC shortens the cecal intubation time. ${ }^{6,7}$ A meta-analysis and systemic review suggests that CAC has a higher polyp detection rate. ${ }^{7,8}$ The author has used a cap for all colonoscopies from 4 years prior. The author's experience shows that CAC has the effect of increasing the cecal intubation rate and shortening the procedure time.

The water immersion technique (i.e., distension of the sigmoid colon with 200-300 mL of water instead of air) may facilitate passage of the endoscope through the sigmoid colon. This technique decreases insertion pain and facilitates completion of difficult colonoscopy. ${ }^{9}$ There has been no report on the use of the water immersion technique in pediatric colonoscopy.

\section{CHANGES IN THE PATTERNS OF PEDIATRIC COLONOSCOPIC EXAMINATION OVER A DECADE}

The author reviewed colonoscopy reports ${ }^{2}$ from Pusan National University Hospital between January 2001 and June 2005, and from Pusan National University Children's Hospital between January 2011 and June 2015. The number of colonoscopic examinations increased from 200 during the period 2001-2005 to 746 during the period 2011-2015. The number of colonoscopic examinations increased 3.73 times over the 10-year period. In the study for 2001-2005, the mean age of the patients was $11.2 \pm 5.8$ years. Neonates and infants accounted for $5.6 \%$ of all cases, and $30 \%$ of patients were aged $>16$ years. Of the 746 patients, $62 \%$ were male and 38\% were female. Therapeutic lower gastrointestinal endoscopies were performed in 37 patients (18.5\%) and 88 patients (11.8\%) during the periods 2001-2005 and 2011-2015, respectively (Table 1). The total number of patients who underwent therapeutic endoscopy also increased. Endoscopic polypectomy accounted for most therapeutic colonoscopy cases.

The main causes that led to colonoscopy were hematochezia (56.0\%), abdominal pain (27.5\%), and diarrhea (3.0\%) during the period 2001-2005 (Table 2). On the other hand, the main causes were abdominal pain (43.7\%), hematochezia (42.5\%) and diarrhea (29.1\%) during the period 2011-2015 (Table 3). The number of patients who underwent colonoscopy because of symptoms related to IBD, such as weight loss, perianal lesion,

Table 1. Classification of Colonoscopic Examination Performed in the Period of 2001-2005 and 2011-2015

\begin{tabular}{lcc}
\hline & \multicolumn{2}{c}{ No. (\%) } \\
\cline { 2 - 3 } & $\mathbf{2 0 0 1 - 2 0 0 5}$ & $\mathbf{2 0 1 1 - 2 0 1 5}$ \\
\hline Diagnostic & $163(81.5)$ & $658(88.2)$ \\
Therapeutic & $37(18.5)$ & $88(11.8)$ \\
Total & $200(100.0)$ & $746(100.0)$ \\
\hline
\end{tabular}


Table 2. Symptoms Leading to Colonoscopy during the Period 2001-2005

\begin{tabular}{lc}
\hline Symptom & No. $(\mathbf{\%})(\boldsymbol{n}=\mathbf{2 0 0})$ \\
\hline Hematochezia & $112(56.0)$ \\
Abdominal pain & $55(27.5)$ \\
Diarrhea & $6(3.0)$ \\
Vomiting & $5(2.5)$ \\
Melena & $3(1.5)$ \\
Hematemesis & $2(1.0)$ \\
Constipation & $2(1.0)$ \\
Others & $15(7.5)$ \\
\hline
\end{tabular}

Table 3. Symptoms Leading to Colonoscopy during the Period 2011-2015

\begin{tabular}{lc}
\hline Symptom & No. $(\%)(\boldsymbol{n}=\mathbf{7 4 6})$ \\
\hline Abdominal pain & $326(43.7)$ \\
\hline Hematochezia & $317(42.5)$ \\
Diarrhea & $217(29.1)$ \\
Weight loss & $113(15.1)$ \\
Vomiting & $49(6.6)$ \\
Perianal lesion & $37(5.0)$ \\
Anemia & $25(3.4)$ \\
Fever & $10(1.3)$ \\
Melena & $8(1.1)$ \\
Oral ulcer & $7(0.9)$ \\
Abdominal distension & $4(0.5)$ \\
Abdominal mass & $2(0.3)$ \\
\hline Others & $27(3.6)$ \\
\hline
\end{tabular}

Data are presented as multiple selection.

and anemia, has increased recently.

The three most common endoscopic diagnoses were juvenile polyp in $20.5 \%$ of patients, Crohn disease (CD) in $13.5 \%$, and proctitis in 10\% during the period 2001-2005 (Table 4). During the period 2011-2015, the three most common endoscopic diagnoses were $\mathrm{CD}$ in $26.8 \%$ of patients, juvenile polyp in $11.5 \%$, and ulcerative colitis in 7.1\% (Table 5). Not only did the number of patients with CD sharply increased from 27 to 200 in 10 years, the proportion of colonoscopic diagnosis also increased from $13.5 \%$ to $26.8 \%$. The number of patients with ulcerative colitis also showed a similar trend.

The number of patients with juvenile polyp increased from 41 to 86 in 10 years, but the proportion of colonoscopic diagnosis decreased from $20.5 \%$ to $11.5 \%$. Diagnosis of pseudomembranous colitis has been found to increase recently. In conclusion, the changes in the patterns of pediatric colonoscopic examination over 10 years seem to be the result of the increase in the number of patients with IBD.
Table 4. Findings of Colonoscopy Performed during the Period 2001-2005

\begin{tabular}{lc}
\hline & No. $(\mathbf{\%})(\boldsymbol{n = 2 0 0 )}$ \\
\hline Normal & $73(36.5)$ \\
Juvenile polyp & $41(20.5)$ \\
Crohn disease & $27(13.5)$ \\
Proctitis & $20(10.0)$ \\
Ulcerative colitis & $10(5.0)$ \\
Infectious colitis & $10(5.0)$ \\
Behcet disease & $3(1.5)$ \\
Tuberculous colitis & $2(1.0)$ \\
\hline Angiodysplasia & $2(1.0)$ \\
Others & $12(6.0)$ \\
\hline
\end{tabular}

Table 5. Findings of Colonoscopy Performed during the Period 2011-2015

\begin{tabular}{lc}
\hline & No. $(\%)(\boldsymbol{n}=\mathbf{7 4 6})$ \\
\hline Normal & $207(27.8)$ \\
Crohn disease & $200(26.8)$ \\
Juvenile polyp & $86(11.5)$ \\
Ulcerative colitis & $53(7.1)$ \\
Infectious colitis & $30(4.0)$ \\
Pseudomembranous colitis & $11(1.5)$ \\
Behcet disease & $6(0.8)$ \\
Proctitis & $6(0.8)$ \\
Tuberculous colitis & $1(0.1)$ \\
Others & $146(19.6)$ \\
\hline
\end{tabular}

Batres et al. ${ }^{3}$ reviewed 1,516 colonoscopy reports from Children's Hospital of Philadelphia from 1994 to 1996 and from 1999 to 2000. The success rate of terminal ileum intubation (TII) was $21.5 \%$ between the years 1994 and 1996, and 65.6\% between 1999 and 2000. During the 5-year period, the success rate of TII increased dramatically and the colonic perforation rate decreased from $0.16 \%$ to $0.11 \%$. In the author's experience, the success rate of TII was $>95 \%$ and the intestinal perforation rate was $0.001 \%$.

\section{COMPLICATIONS OF COLONOSCOPY}

Complications related with sedation during colonoscopy are similar to those reported during upper gastrointestinal endoscopy. The incidence of technical complications during colonoscopy and endoscopist's experience showed some correlation in several studies. ${ }^{10}$

Bleeding after a diagnostic procedure is very rare in children as in adults. Bleeding after colonoscopy was reported to occur 
at an incidence of $1.4 \%$ in a large-scale study. ${ }^{4}$ In the author's study, ${ }^{2}$ bleeding complication did not occur during the period 2001-2005. However, during the period 2010-2015, 2 cases of delayed bleeding occurred after polypectomy. Spontaneous hemostasis developed in one patient. The other patient received angiography and embolization treatment.

Perforation is the most serious complication of colonoscopy in children. The risk ranges from $0.01 \%$ to $0.3 \%{ }^{3,4,11}$ It is usually related to therapeutic colonoscopy such as polypectomy and can be successfully managed with surgical intervention. Recently, endoscopic closure of colon perforation has been attempted in children. ${ }^{12}$ In the author's study, ${ }^{2}$ colonic perforation occurred in 1 patient $(0.5 \%)$ after argon plasma coagulation for ablation of multiple colonic angiodysplasia during the period 2001-2005. However, no colonic perforation occurred at all during the period 2010-2015.

\section{SPECIFIC DIAGNOSTIC AND THERAPEUTIC APPLICATIONS}

\section{Inflammatory bowel disease}

The incidence of IBD in pediatric patients has increased. It is estimated that $15 \%$ to $25 \%$ of patients experience the onset of symptoms before 20 years of age. ${ }^{13}$ Gastrointestinal endoscopy with biopsy is an essential tool for the diagnosis of pediatric IBD as in adults. Endoscopy also helps define the severity and extent of disease, which thereby possibly identifying complications and influencing initial management. ${ }^{14}$

The author reviewed the records of 75 pediatric patients with $\mathrm{CD}$ who had been treated with anti-tumor necrosis factor more than 1 year between 2005 and 2016. The male-to-female ratio of the patients was 41:34. The median age of the patients was 13.95 years old. The disease location of CD was L1 in 5.3\% of the patients, L2 in $14.7 \%$, and L3 in $80.0 \%$. L4A and L4B were diagnosed in $30.0 \%$ and $54.8 \%$ of patients, respectively. More than $85 \%$ of patients with $\mathrm{CD}$ have evidence of terminal ileal involvement, which suggests that total colonoscopy is essential in diagnose of $\mathrm{CD}$.

The author also retrospectively analyzed 49 pediatric patients with ulcerative colitis who received treatment with 1-year minimum follow-up between 2005 and 2016. The median age of the patients was 13.3 years. The disease location at diagnosis was $\mathrm{E} 1$ in $14.3 \%$ of the patients, E2 in $34.7 \%, \mathrm{E} 3$ in $2.0 \%$, and E4 in 49.0\%. Twenty-two patients (44.9\%) showed an atypical distribution of lesions at initial colonoscopy, of whom $8(16.3 \%)$ had appendiceal orifice inflammation and 14 (28.6\%) had patchy/segmental skip lesions. Therefore, total colonoscopy is also seeming to be needed to evaluate the extent and severity of disease in patients with ulcerative colitis.

\section{Lower gastrointestinal tract hemorrhage}

Colonoscopy has become a standard procedure in the diagnosis of hematochezia in children. The benefits of colonoscopy in hematochezia are identification of the site and cause of bleeding, and the possibility of endoscopic intervention. In the author's previous study, ${ }^{15}$ the major causes of hematochezia in children were juvenile polyp (26.4\%), food protein-induced proctocolitis (6.9\%), infectious colitis (5.4\%), and vascular ectasia (5.1\%) (Table 6).

In pediatric patients, the most common cause of hematochezia is polyp. Polyps occur in $1 \%$ of children, and juvenile polyps accounts for almost $90 \% .{ }^{16}$ About $80 \%-90 \%$ of juvenile polyps are solitary and encountered in rectosigmoid area. ${ }^{17}$ However, multiple and proximally located polyp cases are reported in recent studies, which suggests the need for total colonoscopy in all cases. ${ }^{18,19}$ In a previous study by the author, ${ }^{20}$ solitary polyp were noted in 63 patients $(75.9 \%)$ and multiple polyps were found in 20 patients $(24.1 \%)$. The sites of the polyps were rectum and sigmoid colon in $61.4 \%$ and $23.5 \%$ respectively. Eighteen polyps (15.1\%) were found in more-proximal sites than rectosigmoid area. All the patients underwent colonoscopic polypectomy under sedation without complications.

\section{CONCLUSIONS}

Pediatric gastrointestinal endoscopists can perform nearly all endoscopic techniques and have the advantage of being familiar with the specificity of patients, such as age-related physiologies and the spectrum of diseases in children. For accurate

Table 6. Causes of Hematochezia in Children

\begin{tabular}{lc}
\hline & No. (\%) \\
\hline Unknown & $85(30.6)$ \\
Juvenile polyp & $73(26.4)$ \\
\hline Food protein induced proctocolitis & $19(6.9)$ \\
Infectious colitis & $15(5.4)$ \\
Vascular ectasia & $14(5.1)$ \\
Lymphofolliculitis & $13(4.7)$ \\
Nonspecific colitis & $13(4.7)$ \\
Others & $45(16.2)$ \\
Total & $277(100.0)$ \\
\hline
\end{tabular}

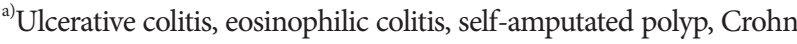
disease, neutropenic enterocolitis, Henoch-Schönlein purpura, Peutz-Jeghers syndrome, ischemic colitis, hemangioma, solitary rectal ulcer, familial adenomatous polyposis, blue rubber nevus syndrome. 
diagnosis and optimal treatment of pediatric patients with lower gastrointestinal disorder, colonoscopy should be more actively employed by pediatric gastroenterologists.

Recent changes in the patterns of pediatric colonoscopic examination over 10 years in Korea seem to result from the increased number of patients with IBD. Therefore, in patients with suspected IBD, total colonoscopy is needed to define the extent and severity of the disease.

\section{Conflicts of Interest}

The author has no financial conflicts of interest.

\section{REFERENCES}

1. Victor LF. Colonoscopy. In: Walker WA, Durie PR, Hamilton JR, Walker-Smith JA, Watkins JB, eds. Pediatric gastrointestinal disease: pathophysiology, diagnosis, management. 2nd ed. St. Louis (MO): Mosby; 1996. p. 1533-1541.

2. Park KH, Park JH. Changes in pediatric gastrointestinal endoscopy: review of a recent hospital experience. Korean J Pediatr Gastroenterol Nutr 2007;10:20-27.

3. Batres LA, Maller ES, Ruchelli E, Mahboubi S, Baldassano RN. Terminal ileum intubation in pediatric colonoscopy and diagnostic value of conventional small bowel contrast radiography in pediatric inflammatory bowel disease. J Pediatr Gastroenterol Nutr 2002;35:320-323.

4. Thakkar K, El-Serag HB, Mattek N, Gilger M. Complications of pediatric colonoscopy: a five-year multicenter experience. Clin Gastroenterol Hepatol 2008;6:515-520.

5. Shumaker DA, Zaman A, Katon RM. A randomized controlled trial in a training institution comparing a pediatric variable stiffness colonoscope, a pediatric colonoscope, and an adult colonoscope. Gastrointest Endosc 2002;55:172-179.

6. Kim HH, Park SJ, Park MI, Moon W, Kim SE. Transparent-cap-fitted colonoscopy shows higher performance with cecal intubation time in difficult cases. World J Gastroenterol 2012;18:1953-1958.

7. Ng SC, Tsoi KK, Hirai HW, et al. The efficacy of cap-assisted colonoscopy in polyp detection and cecal intubation: a meta-analysis of randomized controlled trials. Am J Gastroenterol 2012;107:1165-1173.

8. Westwood DA, Alexakis N, Connor SJ. Transparent cap-assisted colonoscopy versus standard adult colonoscopy: a systematic review and meta-analysis. Dis Colon Rectum 2012;55:218-225.

9. Cadoni S, Leung FW. Water-assisted colonoscopy. Curr Treat Options Gastroenterol 2017;15:135-154.

10. Tringali A, Balassone V, De Angelis P, Landi R. Complications in pediatric endoscopy. Best Pract Res Clin Gastroenterol 2016;30:825-839.

11. Korman LY, Overholt BF, Box T, Winker CK. Perforation during colonoscopy in endoscopic ambulatory surgical centers. Gastrointest Endosc 2003;58:554-557.

12. Tam MS, Abbas MA. Perforation following colorectal endoscopy: what happens beyond the endoscopy suite? Perm J 2013;17:17-21.

13. Goodhand J, Hedin CR, Croft NM, Lindsay JO. Adolescents with IBD: the importance of structured transition care. J Crohns Colitis 2011;5:509-519.

14. Vucelic B. Inflammatory bowel diseases: controversies in the use of diagnostic procedures. Dig Dis 2009;27:269-277.

15. We JH, Park HS, Park JH. The role of colonoscopy in children with hematochezia. Korean J Pediatr Gastroenterol Nutr 2011;14:155-160.

16. Gelb AM, Minkowitz S, Tresser M. Rectal and colonic polyps occurring in young people. N Y State J Med 1962;62:513-518.

17. Toccalino H, Guastavino E, De Pinni F, O’Donnell JC, Williams M. Juvenile polyps of the rectum and colon. Acta Paediatr Scand 1973;62:337340.

18. Mestre JR. The changing pattern of juvenile polyps. Am J Gastroenterol 1986;81:312-314.

19. Durno CA. Colonic polyps in children and adolescents. Can J Gastroenterol 2007;21:233-239.

20. Lee BG, Shin SH, Lee YA, Wi JH, Lee YJ, Park JH. Juvenile polyp and colonoscopic polypectomy in childhood. Pediatr Gastroenterol Hepatol Nutr 2012;15:250-255. 